\title{
Hydrogen and Trimethylsilyl Transfers During \\ EI Mass Spectral Fragmentation of \\ Hydroxycarboxylic and Oxocarboxylic Acid Trimethylsilyl Derivatives
}

\author{
Jean-François Rontani ${ }^{\mathrm{a}}$ and Claude Aubert ${ }^{\mathrm{b}}$ \\ ${ }^{a}$ Laboratoire de Microbiologie de Géochimie et d'Ecologie Marines (UMR 6117), Centre d'Océanologie de \\ Marseille (OSU), Campus de Luminy, Marseille, France \\ ${ }^{\mathrm{b}}$ Laboratoire de Pharmacocinétique et Toxicocinétique (UPRES 3286), Faculté de Pharmacie, Marseille, France
}

This paper, describing electron ionization mass spectral fragmentation of some hydroxycarboxylic and oxocarboxylic acid trimethylsilyl derivatives, focuses on the formation of fragment ions resulting from the interactions between the two functionalities of these compounds. These interactions result in the formation of fragment ions at $\left[\mathrm{CH}_{2}=\mathrm{C}(\mathrm{OTMS})_{2}\right]^{+*},\left[\mathrm{CH}_{2}=\right.$ $\mathrm{CHC}(\mathrm{OTMS})=\mathrm{OTMS}]^{+},[\mathrm{M}-31]^{+},[\mathrm{M}-105]^{+}$, and $\left[\mathrm{M}-\mathrm{RCHO}^{+\cdot}\right.$ in the case of hydroxycarboxylic acid trimethylsilyl derivatives of formula RCHOTMS $\left(\mathrm{CH}_{2}\right)_{\mathrm{n}} \mathrm{COOTMS}$ and at $\left[\mathrm{RC}(\mathrm{OTMS})=\mathrm{CH}_{2}\right]^{+},\left[\mathrm{RC}(=\mathrm{OTMS}) \mathrm{CH}=\mathrm{CH}_{2}\right]^{+}$, and $\left[\mathrm{M}-\mathrm{RC}(=\mathrm{O}) \mathrm{CH}_{2}\right]^{+}$in the case of oxocarboxylic acid trimethylsilyl esters of formula $\mathrm{RC}(=\mathrm{O})\left(\mathrm{CH}_{2}\right)_{\mathrm{n}} \mathrm{COOTMS}$. Some of these fragmentations appeared to be sufficiently specific to be used to characterize these compounds. Several fragmentation pathways involving trimethylsilyl and hydrogen transfers were proposed to explain the formation of these different fragment ions and were substantiated by deuterium labeling. (J Am Soc Mass Spectrom 2008, 19, 66-75) @ 2008 American Society for Mass Spectrometry

\begin{abstract}
0 ilylation is by far the major derivatization procedure for GC/MS analyses [1-3]. Silyl derivatives are formed when active proton displacement (in $-\mathrm{OH},-\mathrm{SH}$, or $-\mathrm{NH}$ groups) by an alkylsilyl group occurs. The most common silylation procedure is trimethylsilylation. Trimethylsilyl derivatives combine thermal stability and high volatility. In general, electron ionization (EI) mass spectra of trimethylsilyl ethers or esters exhibit a significant $[\mathrm{M}-15]^{+}$ion formed by loss of a methyl group bonded to silicon, which is very useful in determining the molecular mass. It is very important to note that EI mass spectra of trimethylsilyl derivatives may be employed not only for molecular weight determinations, but also for structural deductions [4].

Trimethylsilyl group migrations during EI fragmentation process are common $[5,6]$ and take place by means of ion-neutral complexes [7]. These rearrangements are generally considered useful for deducing structures of unknown spectra [8]; however, in some cases, misleading conclusions may be drawn. Though trimethylsilyl group migrations usually occur through five- to eight-member-ring transition states [9], intense long-range migration of the trimethylsilyl group was

Address reprint requests to Dr. J.-F. Rontani, Laboratoire de Microbiologie de Géochimie et d'Ecologie Marines (UMR 6117), Centre d'Océanologie de Marseille (OSU), Campus de Luminy-case 901, 13288 Marseille, France. E-mail: jean-francois.rontani@com.univmed.fr
\end{abstract}

previously observed in the case of trimethylsilyl derivatives of some steroid compounds [8, 10-13]. The capability of the trimethylsilyl group to migrate over a wide range of distances was also demonstrated in the case of semirigid or rigid molecules [5]. Recently, a significant transfer of trimethylsilyl group towards the carbonyl group was also observed during EI fragmentation of the trimethylsilyl derivatives of long-chain $\omega$-hydroxycarboxylic and $\omega$-dicarboxylic acids [14], showing that such migrations may also occur in the case of nonrigid structures.

Hydrogen transfers between distant functionalities during EI fragmentation processes are also well known $[6,15,16]$, for this reaction hydrogen activation is needed and is caused by groups such as keto, amino, ether, trimethylsilyloxy, as well as by chain branching and unsaturation.

In the present work, which is a part of a more general study of the synergistic effects during EI mass fragmentation of polyfunctional compounds [14, 17-19], we describe EI mass spectral fragmentation of several hydroxycarboxylic and oxocarboxylic acid trimethylsilyl derivatives, which involves trimethylsilyl and hydrogen transfers.

The characterization of such compounds appears to be of great environmental importance [20, 21]. Indeed, it was previously demonstrated that autoxidative processes could induce a bias during alkenone-based pa- 
(a)

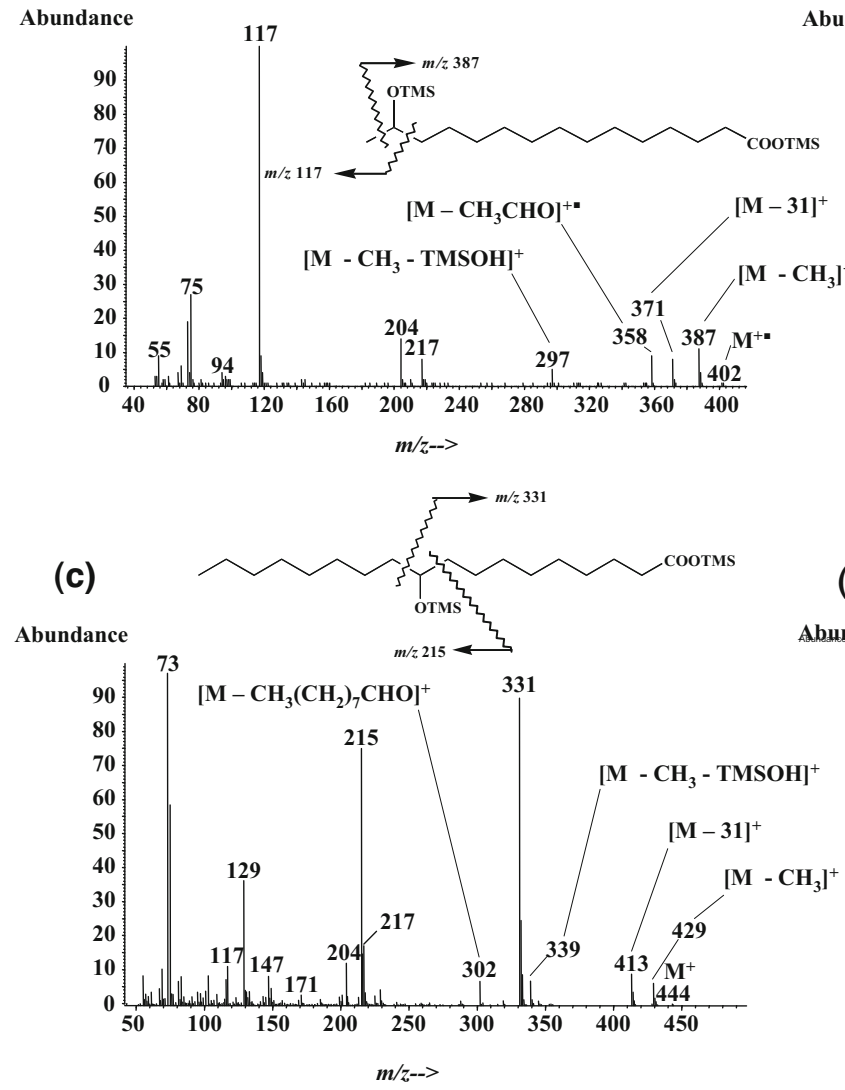

(b)



Figure 1. EI mass spectra of (a) 14-hydroxypentadecanoic, (b) 14-hydroxyhexadecanoic, (c) 10hydroxyoctadecanoic, and (d) 3-hydroxyhexadecanoic acid trimethylsilyl derivatives.

leotemperature estimations [20]. The allylic hydroperoxyketones thus formed are cleaved homolytically and heterolytically in seawater, affording several $(\omega-1)$ - and $(\omega-2)$-oxocarboxylic acids [21]. These compounds and the corresponding hydroxyacids produced after subsequent $\mathrm{NaBH}_{4}$-reduction were proposed as specific markers of alkenone autoxidative alterations in seawater [21]. It is thus essential to be able to differentiate these compounds from isobaric fatty acids or diols, respectively.

To generalize our conclusions, shorter hydroxycarboxylic and oxocarboxylic acids derived from the oxidation of fatty acids were also investigated.

\section{Experimental}

\section{Chemicals}

3-Hydroxyhexadecanoic, 3-hydroxyoctadecanoic, and 6-oxoheptanoic acids were obtained from Sigma-Aldrich. ( $\omega-1)$ - and ( $\omega$-2)-Oxocarboxylic acids ranging from $\mathrm{C}_{14}$ to $\mathrm{C}_{16}$ were obtained by heterolytic cleavage of autoxidation products of $\mathrm{C}_{37}$ and $\mathrm{C}_{38}$ alkenones $[20,21]$. $\mathrm{NaBH}_{4}$ reduction of these oxoacids then afforded the corresponding ( $\omega-1)$ - and ( $\omega$-2)-hydroxycarboxylic acids. 8-Hydroxyoctadec-9-enoic, 10-hydroxyoctadec- 11-enoic, 10-hydroxyoctadecanoic, 11-hydroxyoctadecanoic, 12-hydroxyoctadecanoic, 9-oxooctadecanoic, 10oxooctadecanoic, and 9-oxooctadec-10-enoic acids were prepared according to previously described procedures [22]. 9-Oxodecanoic acid resulted from hydration and retro-aldolization (alkaline hydrolysis) of 9-oxooctadec10-enoic acid. $\mathrm{NaBD}_{4}$ reduction of 10-oxooctadecanoic acid afforded (10- $\left.\mathrm{D}_{1}\right)$-10-hydroxyoctadecanoic acid. Deuteration of 10-oxooctadecanoic acid in the $\alpha$-positions relative to the carbonyl group was carried out according to classic deuterium exchange procedure [23]. Production of a mixture of (11- $\left.\mathrm{D}_{1}\right)-12-$ hydroxyoctadecanoic and (12- $\left.\mathrm{D}_{1}\right)-11$-hydroxyoctadecanoic acids in low yields required two steps: (1) epoxidation of vaccenic acid with 3-chloroperoxybenzoic acid in dry methylene chloride and (2) subsequent reduction of the foregoing epoxide with excess of $\mathrm{NaBD}_{4}$ in diethyl ether/methanol.

\section{Silylation}

Compounds ( $1 \mathrm{mg}$ ) to be silylated were taken up in 300 $\mu \mathrm{L}$ of a mixture of pyridine and BSTFA $(\mathrm{N}, \mathrm{O}-\mathrm{Bis}($ trimethylsilyl)trifluoroacetamide, Supelco Inc., St Quentin Fallavier, France) $(2: 1, \mathrm{vol} / \mathrm{vol})$ and allowed to react at 


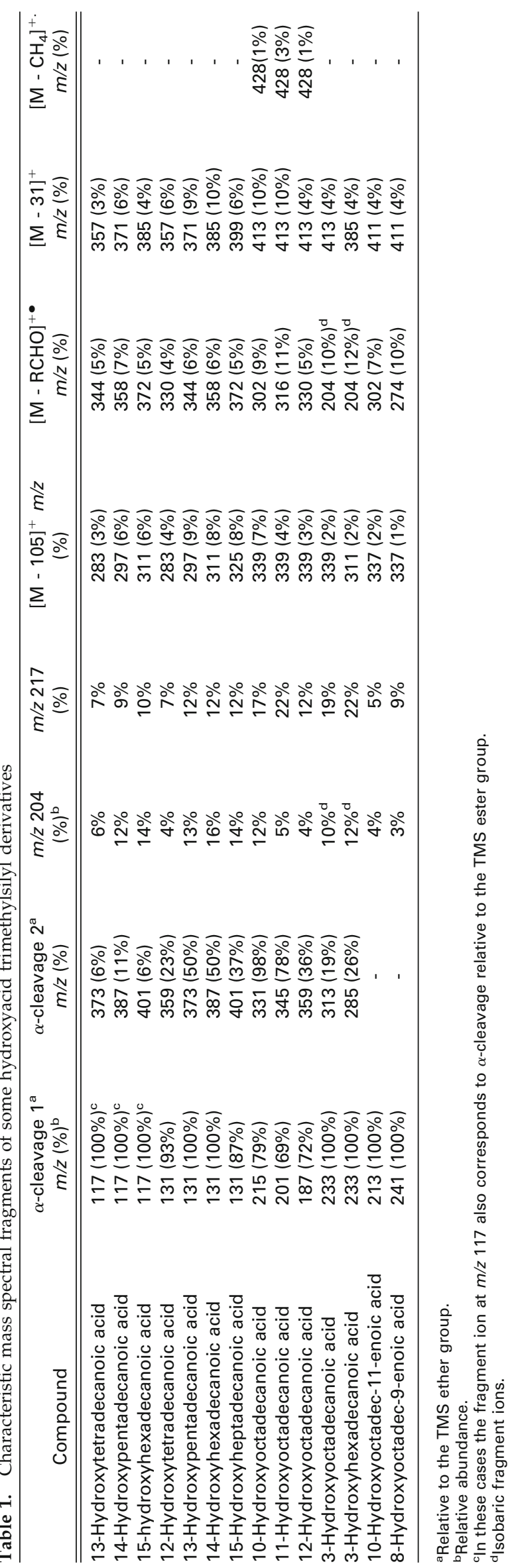

$50{ }^{\circ} \mathrm{C}$ for $1 \mathrm{~h}$. After evaporation to dryness (to eliminate pyridine), the residue was dissolved in ethyl acetate (2 $\mathrm{mL} / \mathrm{mg}$ ) and BSTFA (0.1 mL) (to avoid desilylation) and analyzed by gas chromatography/mass spectrometry (GC/MS).

\section{Mass Spectrometry}

Analyses by gas chromatography/electron impact mass spectrometry were performed with a Hewlett Packard HP 5890 series II plus gas chromatograph connected to a HP 5972 mass spectrometer (Agilent Technologies, Massy, France). The following opera-
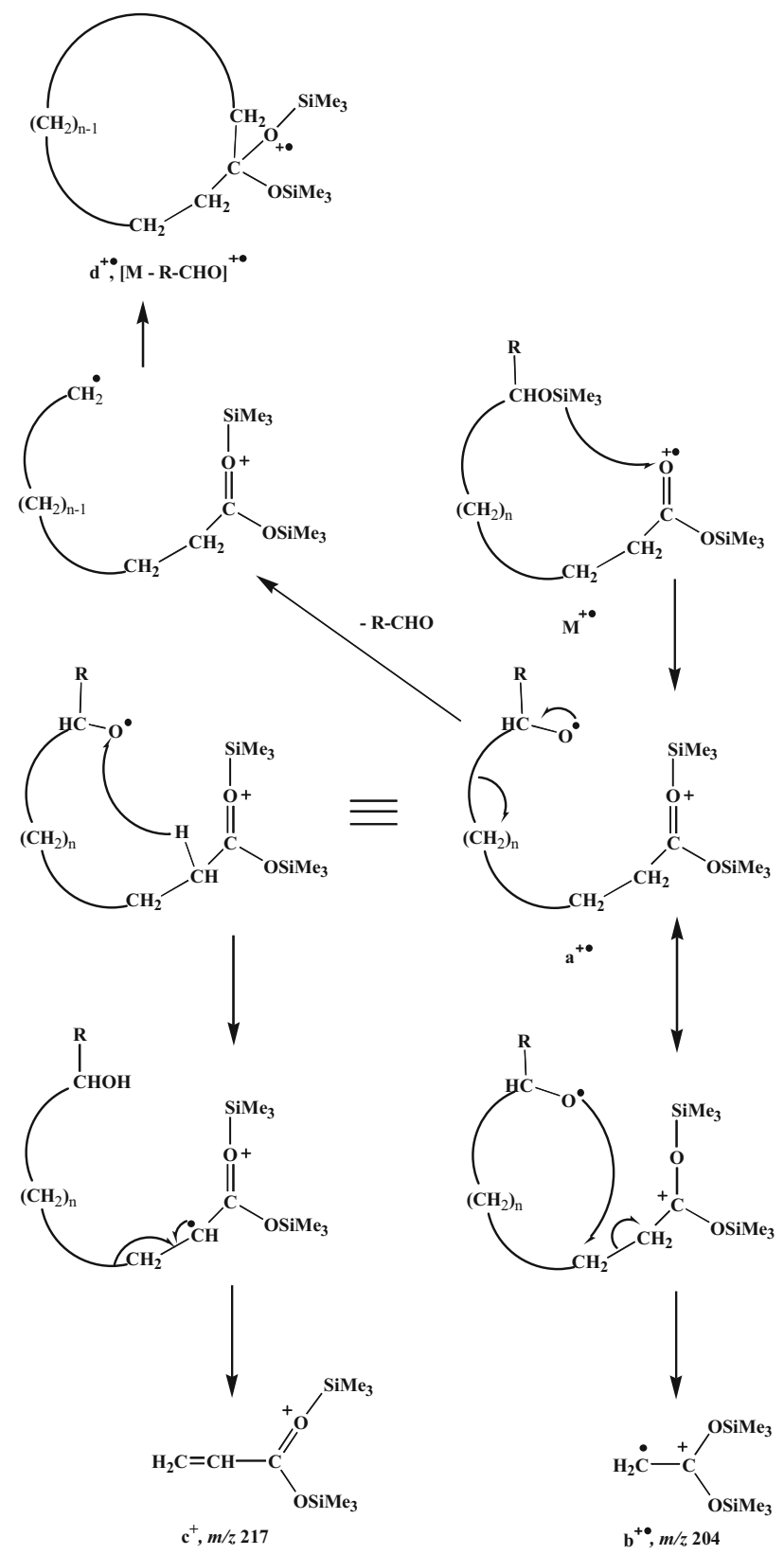

Scheme 1. Proposed formation pathways of ions $\mathbf{b}^{+\cdot}$ (at $m / z$ 204), $\mathbf{c}^{+}($at $m / z 217)$, and $\mathbf{d}^{+\cdot}[\mathrm{M}-\mathrm{RCHO}]^{+\cdot}$ involving trimethylsilyl transfer. 


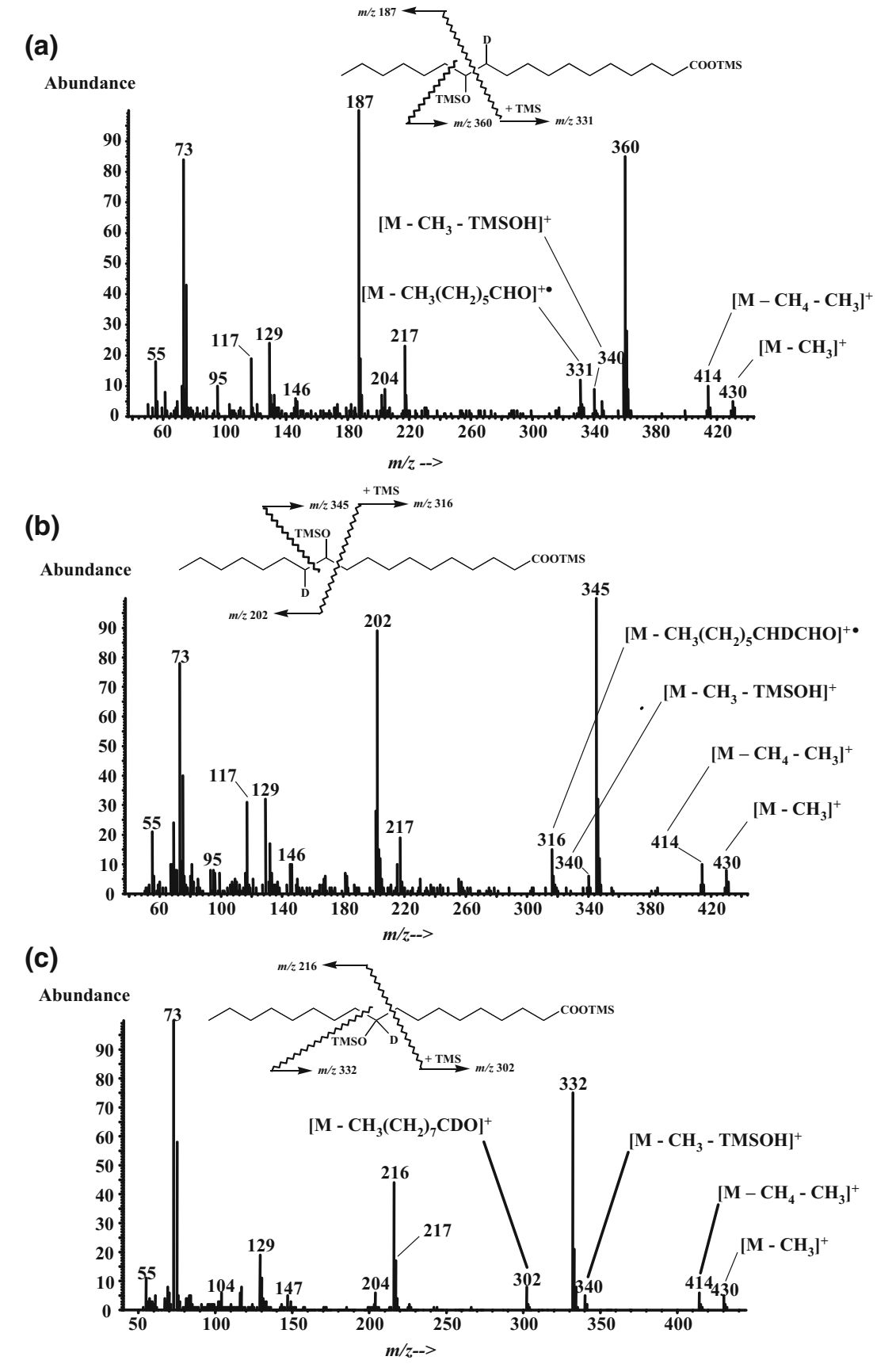

Figure 2. EI mass spectra of (a) (11- $\left.\mathrm{D}_{1}\right)$-12-hydroxyoctadecanoic, (b) (12- $\left.\mathrm{D}_{1}\right)$-11-hydroxyoctadecanoic, and (c) (10-- $\left.\mathrm{D}_{1}\right)$-10-hydroxyoctadecanoic acid trimethylsilyl derivatives.

tive conditions were employed: $30 \mathrm{~m} \times 0.25 \mathrm{~mm}$ (i.d.) capillary column coated with SOLGEL-1 (SGE; film thickness, $0.25 \mu \mathrm{m})$; oven temperature programmed from $60{ }^{\circ} \mathrm{C}$ to $130{ }^{\circ} \mathrm{C}$ at $30{ }^{\circ} \mathrm{C} \mathrm{min}^{-1}$ and then from $130{ }^{\circ} \mathrm{C}$ to $300{ }^{\circ} \mathrm{C}$ at $4{ }^{\circ} \mathrm{C} \mathrm{min}^{-1}$; carrier gas (He) pressure was maintained at 1.04 bar until the end of the temperature program and then programmed from 1.04 bar to 1.5 bar at 0.04 bar $\mathrm{min}^{-1}$; injector (on column with a retention gap) temperature, $50^{\circ} \mathrm{C}$; electron energy, $70 \mathrm{eV}$; source temperature, $170^{\circ} \mathrm{C}$; mass range, 50-700 Th; cycle time, $1.5 \mathrm{~s}$.

\section{Results and Discussion}

Fragmentation of Hydroxycarboxylic Acid Trimethylsilyl Derivatives

We could previously demonstrated [14] that mass spectra of $\omega$-hydroxycarboxylic and $\omega$-dicarboxylic acid trimethylsilyl derivatives exhibited some fragmentations that are lacking in mass spectra of compounds containing only an ester or an ether group. Most of the fragments ions thus formed resulted from trimethylsilyl 
and hydrogen transfers between the two functionalities of the considered molecules.

EI mass spectra of various long-chain hydroxycarboxylic acid trimethylsilyl derivatives of formula RCHOTMS $\left(\mathrm{CH}_{2}\right)_{n}$ COOTMS were investigated (Figure 1 and Table 1) and appeared to be dominated by fragment ions resulting from $\alpha$-cleavages relative to the ionized trimethylsilyl ether group. In the case of 10-hydroxyoctadec-11-enoic and 8-hydroxyoctadec9 -enoic acid trimethylsilyl derivatives, $\alpha$-cleavage only acts on the side of the trimethylsilyl ether group affording an alkyl radical since cleavage on the other side leads to the formation of an unstable and unlikely vinyl radical. These mass spectra also exhibited some other fragment ions, which are lacking in mass spectra of simple trimethylsilyl esters or ethers, and thus result from interactions between the two derivatized functionalities of the molecules. This is the case notably for the ions at $\mathrm{m} / \mathrm{z} 204$ and 217, which were previously observed in EI mass spectra of $\omega$-hydroxycarboxylic and $\omega$-dicarboxylic acid trimethylsilyl derivatives [14] and whose the formation was attributed to an initial trimethylsilyl transfer from the ether group to the ionized ester group. In the case of hydroxycarboxylic acid trimethylsilyl derivatives of formula RCHOTMS $\left(\mathrm{CH}_{2}\right)_{\mathrm{n}}$ COOTMS, this transfer affords the distonic ion $\mathrm{a}^{+\cdot}$ (Scheme $\left.\mathbf{1}\right)$, which may then either undergo $\beta$-cleavage giving the radical ion $\mathbf{b}^{+\cdot}$ at $m / z 204$, or $\gamma$-cleavage after transfer of a hydrogen atom from the carbon in $\alpha$ position relative to the ionized ester group to the residual alkoxyl radical affording the ion $\mathbf{c}^{+}$at $\mathrm{m} / z 217$. The formation of ions corresponding to [M - RCHO] ${ }^{+\cdot}$ (Figure 1 and Table 1) can be attributed to $\beta$-cleavage of the alkoxyl radical of the ion $\mathbf{a}^{+\cdot}$ giving the cyclic ion $\mathbf{d}^{+\cdot}$ (Scheme 1). The involvement of such a pathway is well supported by the presence of fragment ions at $\mathrm{m} / \mathrm{z} 331,316$, and 302 in EI mass spectra of $\left(11-\mathrm{D}_{1}\right)$ 12-hydroxyoctadecanoic, (12- $\left.\mathrm{D}_{1}\right)$-11-hydroxyoctadecanoic and $\left(10-\mathrm{D}_{1}\right)-10$-hydroxyoctadecanoic acid trimethylsilyl derivatives, respectively (Figure 2). It is interesting to note that the ions $[\mathrm{M}-\mathrm{RCHO}]^{+\cdot}$ and $\mathbf{b}^{+\cdot}$ are isobaric $(\mathrm{m} / \mathrm{z} 204)$ in the case of 3-hydroxycarboxylic acid trimethylsilyl derivatives (Figure 1d, Table 1).

Mass spectra of the hydroxycarboxylic acid trimethylsilyl derivatives investigated also exhibit peaks corresponding to $[\mathrm{M}-105]^{+}$and $[\mathrm{M}-31]^{+}$(Figure 1 and Table 1), which are lacking in mass spectra of compounds containing only an ester or an ether group. The formation of the peak at $[\mathrm{M}-105]^{+}$may be simply attributed to successive losses of a neutral molecule of trimethylsilanol and a methyl radical from the molecular ion. In contrast, the formation of the peak at [M $31]^{+}$appears to be more difficult to explain. To explain the formation of a similar ion in mass spectra of $\omega$-hydroxycarboxylic and $\omega$-dicarboxylic acids trimethylsilyl derivatives, we previously proposed some pathways involving initial hydrogen transfer from the ether

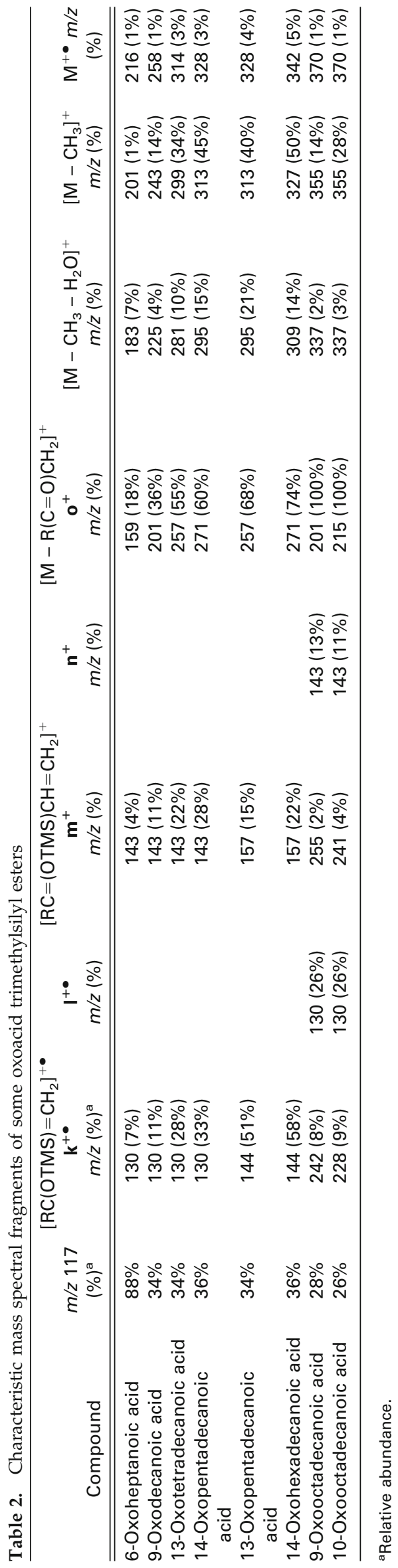




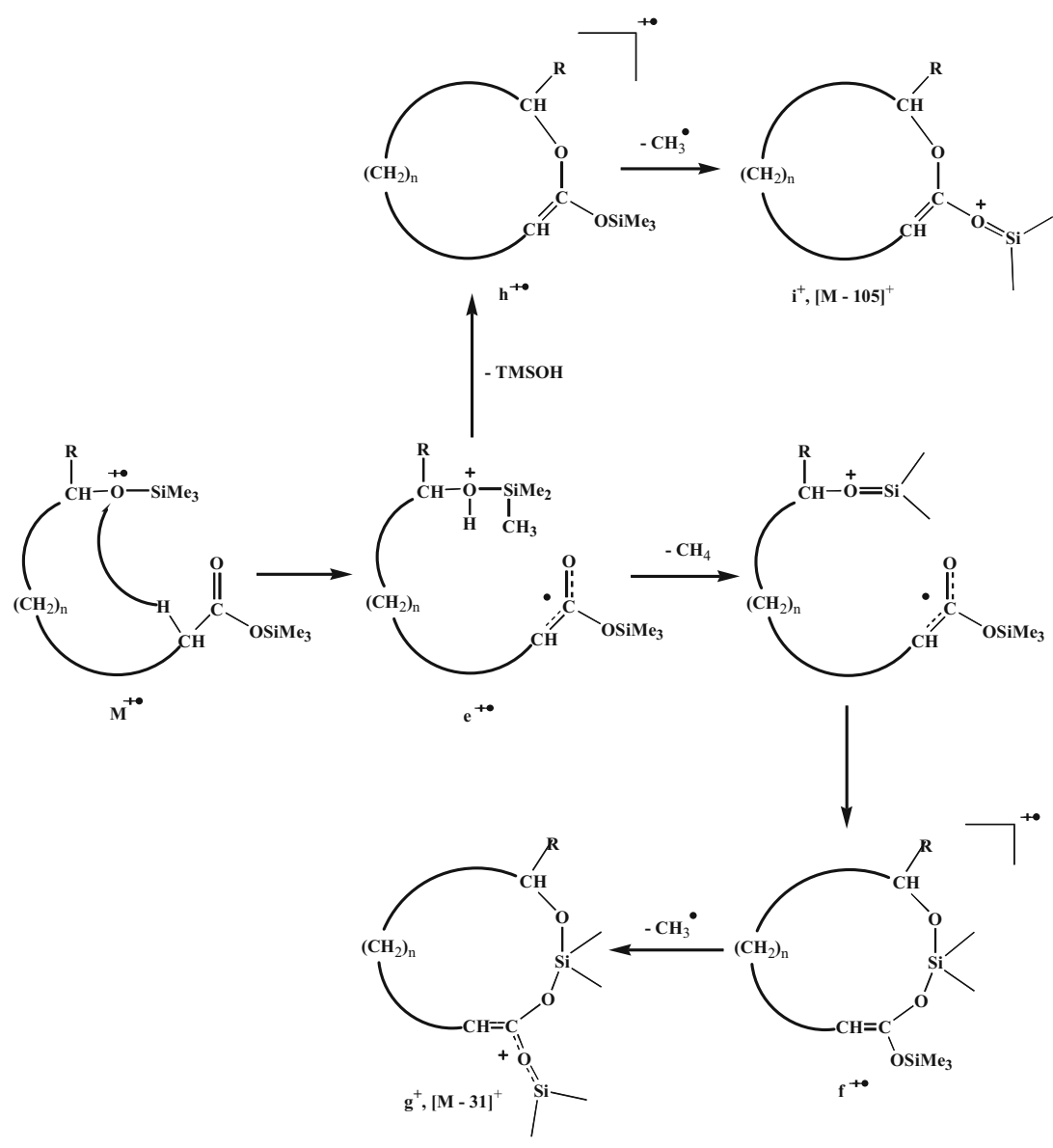

Scheme 2. Proposed formation pathways of ions $\mathbf{g}^{+}\left(\right.$at $\left.[\mathrm{M}-31]^{+}\right)$and $\mathbf{i}^{+}\left(\right.$at $\left.[\mathrm{M}-105]^{+}\right)$involving hydrogen transfer.

group to the ionized ester group and subsequent losses of a neutral molecule of methane and a methyl radical [14]. Indeed, the loss of methane is often observed in EI mass spectra of trimethylsilyl derivatives [24, 25]. The presence of a peak at $\mathrm{m} / \mathrm{z} 414$ (corresponding to [M $\left.31]^{+}\right)$in the EI mass spectrum of $\left(10-\mathrm{D}_{1}\right)-10$-hydroxyoctadecanoic acid trimethylsilyl derivative (Figure 2c) leads us to discard such a possibility. Indeed, the transfer of the deuterium atom from the ether group to the ionized ester group would have resulted in a shift of this peak to $\mathrm{m} / \mathrm{z} 413\left[\mathrm{M}-\mathrm{CH}_{3} \mathrm{D}-\mathrm{CH}_{3}\right]^{+}$. We thus propose the mechanisms described in the Scheme 2 to explain the formation of these ions. This pathway involves initial hydrogen transfer from the carbon in $\alpha$ position relative to the ester group to the ionized oxygen atom of the ether group. The resulting distonic ion $\mathbf{e}^{+\cdot}$ (where the radical is stabilized by conjugation) may then loose a neutral molecule of methane by way of a four-membered hydrogen rearrangement with charge retention [6] to give after cyclization the radical ion $\mathbf{f}^{+}$. Subsequent loss of a methyl radical by this ion $\mathbf{f}^{+\cdot}$ yields the ion $\mathbf{g}^{+}$at $[\mathrm{M}-31]^{+}$stabilized by conjugation. The involvement of such a pathway is in good agreement with the presence of a peak at $\mathrm{m} / \mathrm{z} 414$ in the EI mass spectrum of $\left(10-\mathrm{D}_{1}\right)-10$-hydroxyoctadecanoic acid trimethylsilyl derivative (Figure 2c) and is also well supported by the presence of a weak peak corresponding to the fragment ion $\mathrm{f}^{+\cdot}$ at $\left[\mathrm{M}-\mathrm{CH}_{4}\right]^{++}$in EI mass spectra of some hydroxycarboxylic acid trimethylsilyl derivatives (Table 1). The subsequent losses of a neutral molecule of trimethylsilanol and a methyl radical by the ion $\mathrm{e}^{+ \text {. }}$ (Scheme 2) constitute potential sources of the ion at [M $105]^{+}$; however, this ion can also be formed from the molecular ion without hydrogen transfer.

\section{Fragmentation of Oxocarboxylic Acid Trimethylsilyl Esters}

EI mass spectra of oxocarboxylic acid trimethylsilyl esters of formula $\mathrm{RC}(=\mathrm{O})\left(\mathrm{CH}_{2}\right)_{\mathrm{n}} \mathrm{COOTMS}$ (Figure 3, Table 2) exhibit fragment ions at $m / z 117,129,145$, and $\left[\mathrm{M}-\mathrm{CH}_{3}\right]^{+}$ resulting from classical fragmentation of the TMS ester groups [14]. Classical $\gamma$-hydrogen rearrangement of the keto group also affords the ion $\left[\mathrm{RC}(\mathrm{OH})=\mathrm{CH}_{2}\right]^{+}$. If the keto group possesses $\gamma$-hydrogen atoms in both chains consecutive rearrangements yielding the ion $\left[\mathrm{CH}_{3} \mathrm{C}(\mathrm{OH})\right.$ $\left.=\mathrm{CH}_{2}\right]^{+\cdot}$ can occur. The presence of a significant peak at $[\mathrm{M}-33]^{+}$can be attributed to successive losses of a neutral molecule of $\mathrm{H}_{2} \mathrm{O}$ and a methyl radical. Indeed, the loss of water is often observed in EI mass spectra of long-chain ketones [6]. 
(a)

Abundance

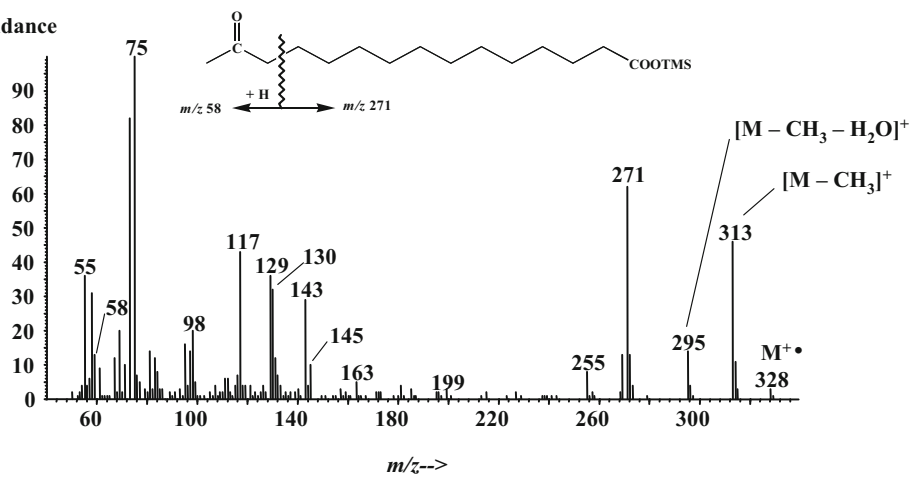

(b)

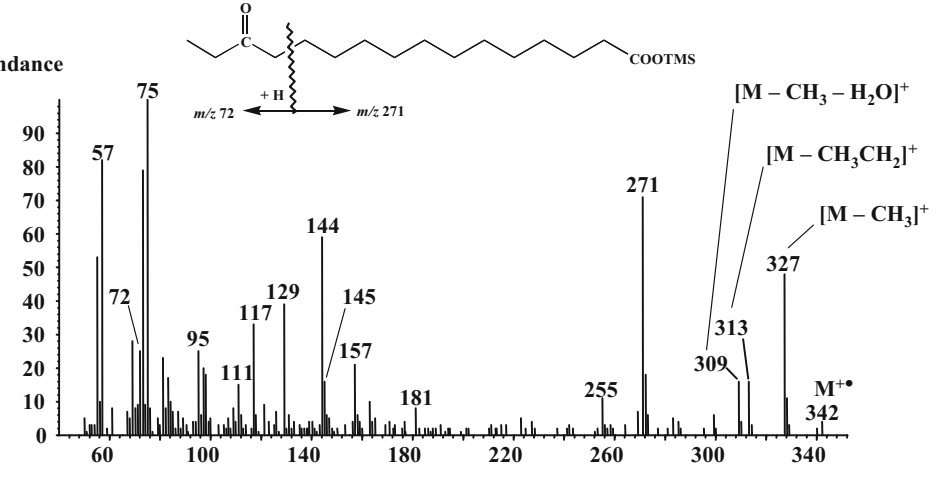

(c)

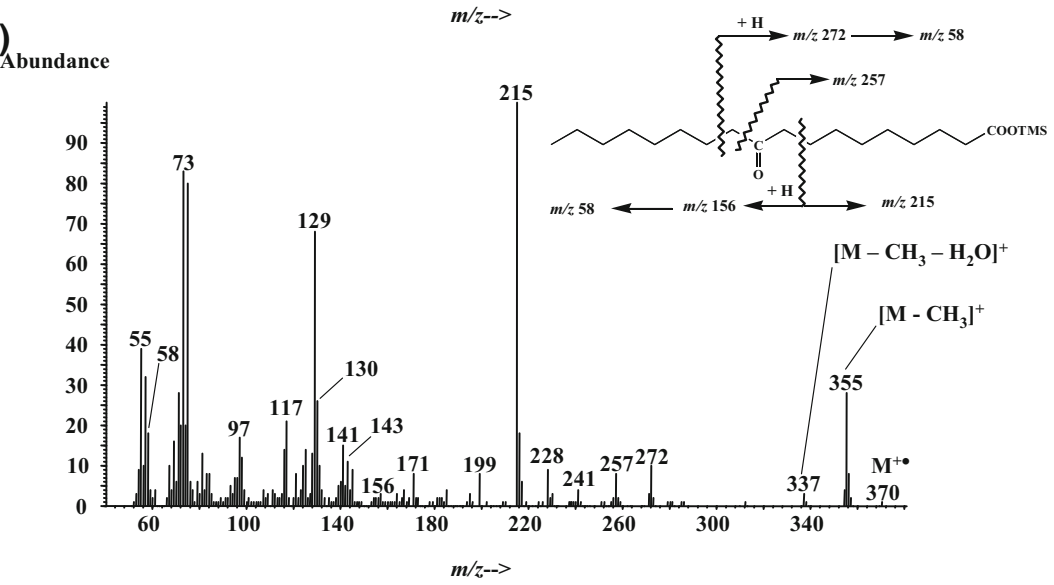

Figure 3. EI mass spectra of (a) 14-oxopentadecanoic, (b) 14-oxohexadecanoic, and (c) 10-oxooctadecanoic acid trimethylsilyl esters.

These EI mass spectra also show strong fragment ions resulting from the interactions between the keto and ester functionalities $\left(\left[\mathrm{RC}(\mathrm{OTMS})=\mathrm{CH}_{2}\right]^{+\cdot},[\mathrm{RC}(=\right.$ $\left.\mathrm{OTMS}) \mathrm{CH}=\mathrm{CH}_{2}\right]^{+}$and $\left[\mathrm{M}-\mathrm{RC}(=\mathrm{O}) \mathrm{CH}_{2}\right]^{+}$) (Figure 3 , Table 2). These fragment ions are lacking or present in very weak proportions in EI mass spectra of ketones [6] and TMS esters [14].

To explain the formation of the ions [RC(OTMS) = $\left.\mathrm{CH}_{2}\right]^{+\cdot}$, we propose the pathways described in Scheme 3 involving an initial trimethylsilyl transfer from the ester group to the ionized ketone. The distonic ion $\mathbf{j}^{+ \text {. }}$ thus formed may then undergo $\beta$-cleavage giving the radical ion $\left[\mathrm{RC}(\mathrm{OTMS})=\mathrm{CH}_{2}\right]^{+\cdot}\left(\mathbf{k}^{+\cdot}\right)$. When R- has more than two carbon atoms, subsequent $\gamma$-hydrogen rearrangement of the ion $\mathbf{k}^{+\cdot}$ affords the ion $\mathbf{1}^{+\cdot}$ at $\mathrm{m} / \mathrm{z}$
130 (Figure 3c). Transfer of a hydrogen atom from the carbon in $\alpha$-position relative to the ionized keto group of ion $\mathrm{j}^{+\cdot}$ to the carboxyl radical and subsequent $\gamma$-cleavage may afford the ion [RC( = OTMS $) \mathrm{CH}=$ $\left.\mathrm{CH}_{2}\right]^{+}\left(\mathbf{m}^{+}\right)$. When $\mathrm{R}$ - is longer than ethyl, the ion $\mathbf{m}^{+}$ can then undergo $\gamma$-hydrogen rearrangement giving the ion $\mathbf{n}^{+}$at $m / z 143$ (Figure 3c). The shift of the ions $\mathbf{k}^{+}$, $\mathbf{1}^{+\cdot}, \mathbf{m}^{+}$, and $\mathbf{n}^{+}$to $\mathrm{m} / z 232,134,244$, and 146 , respectively, in the mass spectrum of $\left(9-\mathrm{D}_{2}, 11-\mathrm{D}_{2}\right)-10$-oxooctadecanoic acid trimethylsilyl ester (Figure 4) is consistent with such pathways.

We propose the fragmentation pathways described in the Scheme 4 to explain the formation of the intense fragment ions at $\left[\mathrm{M}-\mathrm{RC}(=\mathrm{O}) \mathrm{CH}_{2}\right]^{+}$in the mass spectra of oxocarboxylic acid trimethylsilyl esters. 


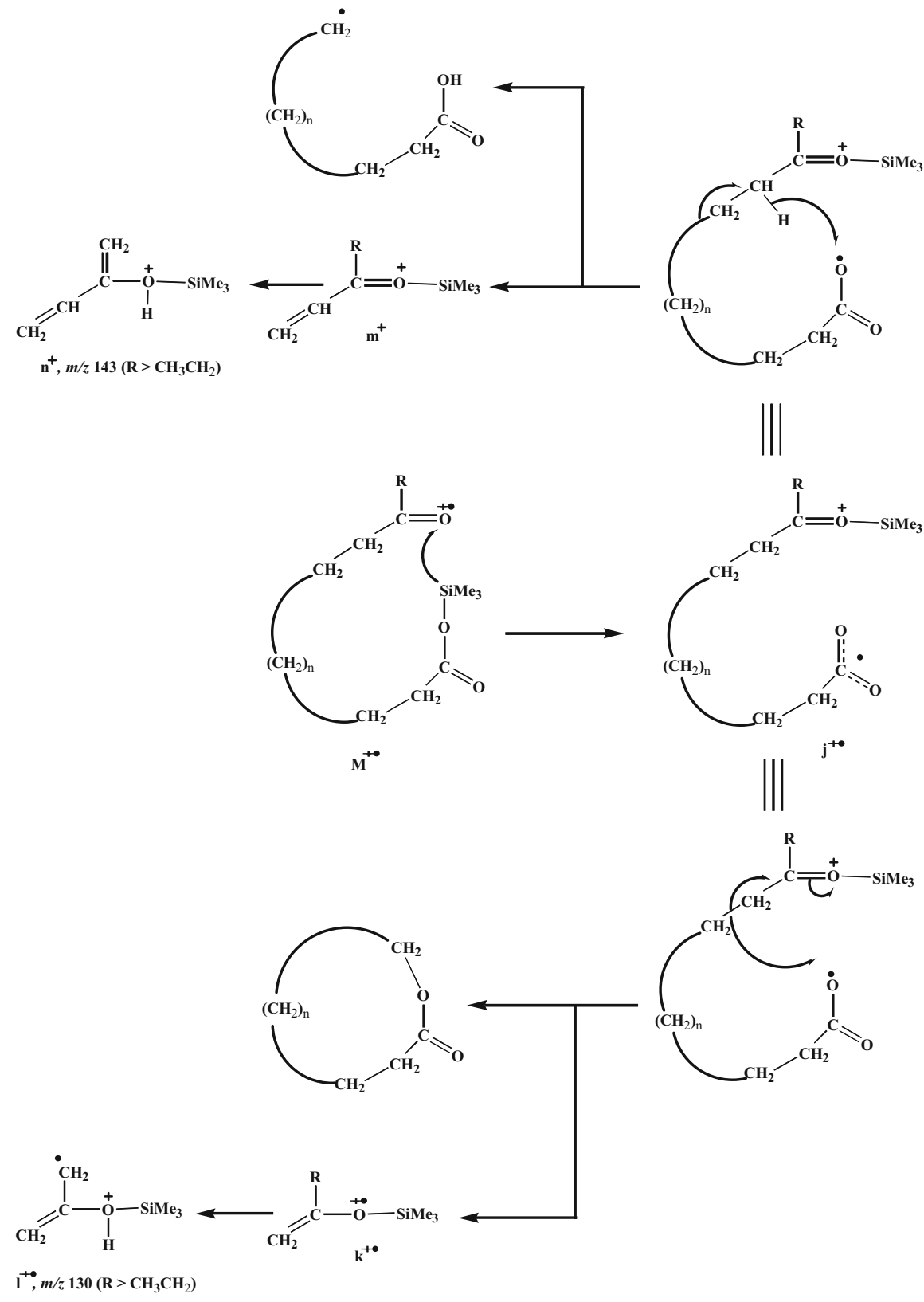

Scheme 3. Proposed formation pathways of ions $\mathbf{1}^{+\cdot}$ and $\mathbf{n}^{+}$involving trimethylsilyl transfer.

These pathways involve initial hydrogen transfer from the carbon in $\gamma$-position relative to the keto group to the ionized ester group and subsequent $\beta$-cleavage relative to the keto group affording the ion $\mathbf{o}^{+}$and the radical $\mathbf{p}$. stabilized by conjugation. These pathways are well supported by the presence of a peak at $\mathrm{m} / \mathrm{z} 215$ in the mass spectrum of $\left(9-\mathrm{D}_{2}, 11-\mathrm{D}_{2}\right)$-10-oxooctadecanoic acid trimethylsilyl ester (Figure 4) corresponding to [M $\left.\mathrm{CH}_{3}\left(\mathrm{CH}_{2}\right)_{6} \mathrm{CD}_{2} \mathrm{C}(=\mathrm{O}) \mathrm{CD}_{2}\right]^{+}$.

\section{Conclusions}

It is generally considered that a molecule containing two functional groups can undergo EI mass fragmentations that are not found for those with either group alone. Examination of EI mass spectra of hydroxycarboxylic and oxocarboxylic acid trimethylsilyl derivatives allowed us to confirm this assertion.

Although mass spectra of hydroxycarboxylic acid trimethylsilyl derivatives of formula RCHOTMS $\left(\mathrm{CH}_{2}\right)_{\mathrm{n}} \mathrm{COOTMS}$ are dominated by fragment ions resulting from classic $\alpha$-cleavage relative to the trimethylsilyloxy ether group, they also exhibit fragment ions at $\mathrm{m} / \mathrm{z}$ 204, 217, $[\mathrm{M}-31]^{+},[\mathrm{M}-105]^{+}$, and $[\mathrm{M}-\mathrm{RCHO}]^{+}$ resulting from trimethylsilyl and hydrogen transfers between the two functionalities of the molecule. These fragment ions could be very useful to characterize these compounds and notably to differentiate them from isobaric diol trimethylsilyl derivatives.

Mass spectra of oxocarboxylic acid trimethylsilyl 


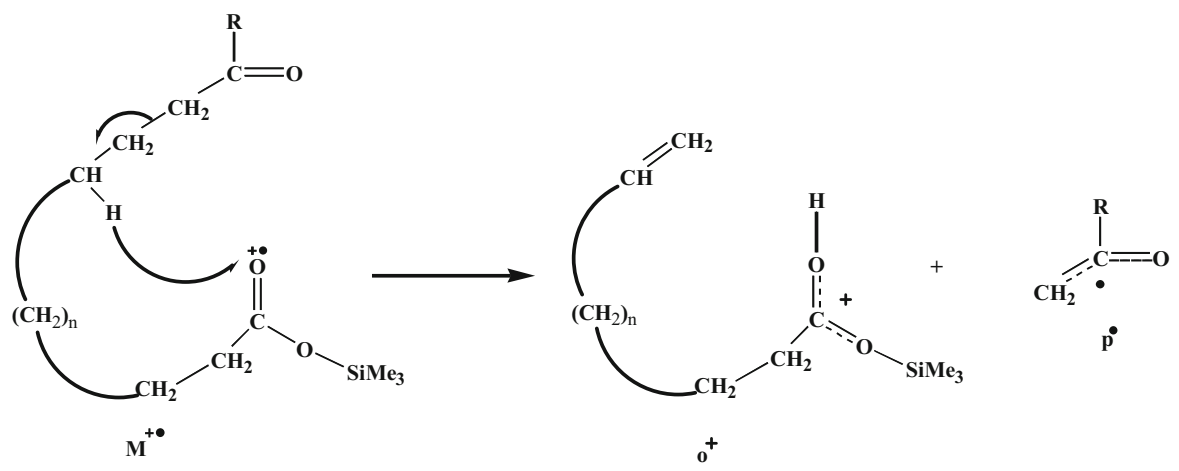

Scheme 4. Proposed formation pathways of ion $\mathbf{o}^{+}$at $\left[\mathrm{M}-\mathrm{RC}(=\mathrm{O}) \mathrm{CH}_{2}\right]^{+}$involving hydrogen transfer.
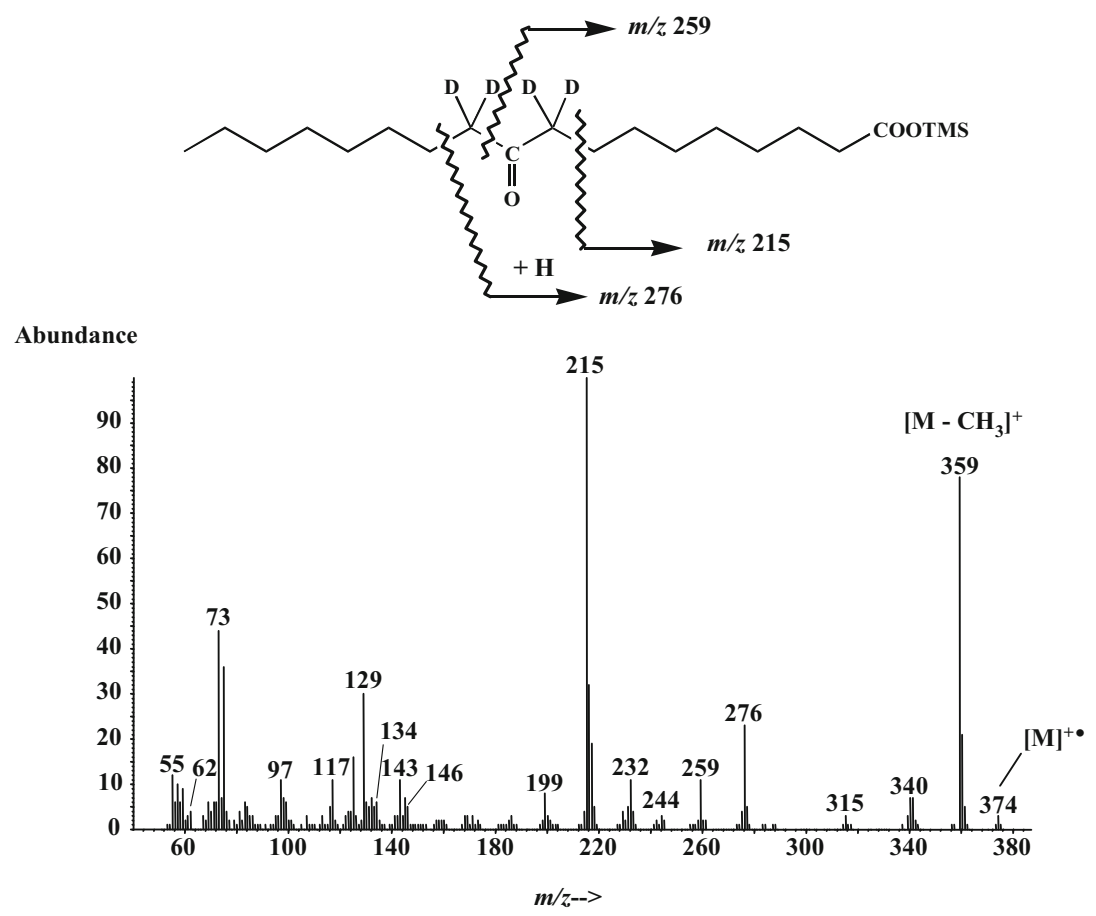

Figure 4. EI mass spectrum of $\left(9-\mathrm{D}_{2}, 11-\mathrm{D}_{2}\right)-10$-oxooctadecanoic acid trimethylsilyl ester.

esters of formula $\mathrm{RC}(=\mathrm{O})\left(\mathrm{CH}_{2}\right)_{\mathrm{n}}$ COOTMS show fragment ions at $\left[\mathrm{RC}(\mathrm{OTMS})=\mathrm{CH}_{2}\right]^{+\cdot},[\mathrm{RC}(=\mathrm{OTMS}) \mathrm{CH}$ $\left.=\mathrm{CH}_{2}\right]^{+}$, and $\left[\mathrm{M}-\mathrm{RC}(=\mathrm{O}) \mathrm{CH}_{2}\right]^{+}$also resulting from trimethylsilyl and hydrogen transfers between the two functionalities of the molecule. These specific fragment ions could be very useful in differentiating these compounds from isobaric fatty acid trimethylsilyl esters.

\section{Acknowledgments}

The authors acknowledge support for this work by grants from the Centre National de la Recherche Scientifique (CNRS) and the Université de la Méditerranée.

\section{References}

1. Segura, J.; Ventura, R.; Jurado, C. Derivatization Procedures for Gas Chromatographic-Mass Spectrometric Determination of Xenobiotics in
Biological Samples, with Special Attention to Drugs of Abuse and Doping Agents. J. Chromatogr. B 1998, 713, 61-90.

2. Pierce, A. E. Silylation of Organic Compounds; Pierce Chemical Co.: Rockford, IL, 1982; p 35.

3. Evershed, R. P. Handbook of Derivatives for Chromatography, 2nd ed; Wiley: Chichester, 1993; p 51

4. Goad, L. J.; Akihisa, T. Analysis of Sterols; Blackie Academic and Professional: London, 1997; p 156

5. Kingston, D. G. I.; Bursey, J. T.; Bursey, M. M. Intramolecular Hydrogen Transfer in Mass Spectra. II. The McLafferty Rearrangement and Related Reactions. Chem. Rev. 1974, 74, 215-242.

6. McLafferty, F. W. Interpretation of Mass Spectra, 4th ed.; University Science Books: Sausalito, CA, 1993; p 219.

7. Byun, J.; Gross, M. L.; George, M.; Parees, D. M.; Kamzelski, A. Z.; Swijter, D. F. H.; Willcox, D. A. Investigation of Group Migration in the Fragmentation of bis(Trimethylsilyl) Ethers of Diols Separated by Rigid Groups. J. Mass Spectrom. 1997, 32, 71-80.

8. Annan, M.; Lequesne, P. W.; Vouros, P. Trimethylsilyl Group Migration in the Mass Spectra of Trimethylsilyl Ethers of Cholesterol Oxidation Products. Product Ion Characterization by Linked-Scan Tandem Mass Spectrometry. J. Am. Soc. Mass Spectrom. 1993, 4, 327-335.

9. Brooks, C. J. W. Some Aspects of Mass Spectrometry in Research on Steroids. Philos. Trans. R. Soc. Lond. Ser. A 1979, 253, 53-67.

10. Longevialle, P. Ion Neutral Complexes in Unimolecular Reactivity of Organic Cations in the Gas Phase. Mass Spectrom. Rev. 1992, 11, 157-192. 
11. Brooks, C. J. W.; Harvey, D. J.; Middleditch, B. S. The Origin of the [M $56]^{++}$Ion in the Mass Spectra of Trimethylsilyl Ethers of Dihydroepiandrosterone and Related Compounds. J. Org. Chem. 1972, 37, 3365.

12. Brooks, C. J. W.; Harvey, D. J.; Middleditch, B. S.; Vouros, P. Mass Spectra of Trimethylsilyl Ethers of Some $\Delta-5,3-\beta$-Hydroxy $\mathrm{C}_{19}$ Steroids. Org. Mass Spectrom. 1973, 7, 925-948.

13. Smith, A. G.; Gaskell, S. J.; Brooks, C. J. W. Trimethylsilyl Group Migration During Electron Impact and Chemical Ionization Mass Spectrometry of the Trimethylsilyl Ethers of 20-Hydroxy-5 $\alpha$-Pregnan-3Ones and 20-Hydroxy-4-Pregen-3-Ones. Biomed. Mass Spectrom. 2005, 3, 161-165.

14. Rontani, J.-F.; Aubert, C. Trimethylsilyl Transfer During Electron Ionization Mass Spectral Fragmentation of Some $\omega$-Hydroxycarboxylic and $\omega$-Dicarboxylic acid Trimethylsilyl Derivatives and the Effect of Chain Length. Rapid Commun. Mass Spectrom. 2004, 18, 1889-1895.

15. Liedtke, R. J.; Gerrard, A. F.; Diekman, J.; Dierassi, C. Mass Spectrometry in Structural and Stereochemical Problems. CCXV. Behavior of Phenyl-Substituted $\alpha, \beta$-Substituted Ketones Upon Electron ImpactPromotion of Hydrogen Rearrangement Processes. J. Org. Chem. 1972, 37, 776-789.

16. Meyerson, S.; Leitch, L. C. Organic Ions in the Gas Phase. XVII. A Bicyclic Doubly Hydrogen-Bridged Transition State in Decomposition of 6-Substituted Alkanoic Acids and Esters. J. Am. Chem. Soc. 1966, 88, $56-60$.

17. Rontani, J.-F.; Rabourdin, A.; Aubert, C. Electron Ionization Mass Spectral Fragmentation of Some Isoprenoid Glycidic Ethers. Rapid Commun. Mass Spectrom. 2001, 15, 2091-2095.
18. Rontani, J.-F.; Aubert, C. Electron Ionization Mass Spectral Fragmentation of Derivatized 4,5- and 5,6-Epoxysterols. Rapid Commun. Mass Spectrom. 2004, 18, 955-959.

19. Rontani, J.-F.; Aubert, C. Electron Ionization Mass Spectral Fragmentation of Cholestane- $3 \beta, 4 \alpha, 5 \alpha$-Triol and Cholestane- $3 \beta, 5 \alpha, 6 \alpha$-Triol bisand tris-Trimethylsilyl Derivatives. Rapid Commun. Mass Spectrom. 2005, 19, 1921-1927.

20. Rontani, J.-F.; Marty, J.-C.; Miquel, J.-C.; Volkman, J. K. Free Radical Oxidation (Autoxidation) of Alkenones and Other Microalgal Lipids in Seawater. Org. Geochem. 2006, 37, 354-368.

21. Rontani, J.-F., Harji, R., Volkman, J. K. Biomarkers Derived from Heterolytic and Homolytic Cleavage of Allylic Hydroperoxides Resulting from Alkenone Autoxidation. Mar. Chem. 2007, in press.

22. Marchand, D.; Rontani, J.-F. Visible Light-Induced Oxidation of Lipid Components of Purple Sulfur Bacteria: A Significant Process in Microbial Mats. Org. Geochem. 2003, 34, 61-79.

23. Lund, E.; Budzikiewicz, H.; Wilson, J. M.; Djerassi, C. Mass Spectrometry in Structural and Stereochemical Problems. XXI. Fragmentation and Hydrogen Transfer Reactions After Electron Impact on $\beta$-Decalones. J. Am. Chem. Soc. 1963, 85, 1528-1534.

24. Spirau, F.; Bourgeois, G.; Dunoguès, J. Gas Chromatography/Mass Spectrometry for the Study of the Polysilylation of 1-Bromonaphtalene. Detection of New Polysilylated Products. Rapid Commun. Mass Spectrom. 1998, 12, 1419-1424.

25. Leblanc, D.; Audier, H. E.; Denhez, J. P. Reaction of Silyl Cations with Ketones in the Gas Phase. J. Mass Spectrom. 1999, 34, 969-974. 